European Polymer Journal 49 (2013) 1196-1203

doi: http://dx.doi.org/10.1016/j.eurpolymj.2013.02.018

\title{
Processing Stabilisation of PE with a Natural Antioxidant, Curcumin
}

\author{
Dóra Tátraaljai $^{1,2}$, Balázs Kirschweng ${ }^{1,2}$, János Kovács ${ }^{1,2}$, Enikő Földes ${ }^{1,2^{*}}$, \\ Béla Pukánszky ${ }^{1,2}$
}

${ }^{1}$ Institute of Materials and Environmental Chemistry, Research Centre for Natural Sciences, Hungarian Academy of Sciences, H-1525 Budapest, P.O. Box 17, Hungary

${ }^{2}$ Laboratory of Plastics and Rubber Technology, Department of Physical Chemistry and Materials Science, Budapest University of Technology and Economics, H-1521 Budapest, P.O. Box 91, Hungary

\begin{abstract}
The potential use of natural antioxidants for polyolefin stabilisation came into the centre of attention because of some doubts about the effects of the reaction products of synthetic phenolic antioxidants on human health. The effect of curcumin on the melt stability of polyethylene was investigated in this paper with and without a phosphonite stabiliser by using multiple extrusions. Irganox 1010 was applied as reference phenolic antioxidant. Curcumin was characterised by FT-IR and UV-VIS spectroscopy, as well as by thermal analysis. Its stabilisation efficiency was determined by measuring the chemical structure, the rheological properties, the residual thermo-oxidative stability, and the colour of the polymer. The results reveal that the melt stabilising efficiency of curcumin is superior to that of the synthetic antioxidant investigated and is further enhanced by the addition of the phosphonite secondary antioxidant. The changes in the characteristics of the polymer indicate that besides the phenolic $\mathrm{OH}$ groups also the linear linkage between the two methoxyphenyl rings of curcumin participates in the stabilisation reactions.
\end{abstract}


Key words: natural antioxidant, curcumin, polyethylene, stabilisation

\section{Introduction}

Polyethylene (PE) is a commodity polymer applied in many areas. The material is exposed to heat, shear, and a small amount of oxygen during processing. Without adequate stabilisation this leads to degradation reactions: chain scission and/or chain extension, which result in the deterioration of mechanical properties and ultimately the formation of a network. Synthetic antioxidants are used to hinder these reactions in practice, but several questions were raised earlier regarding the effect of the reaction products of phenolic antioxidants on human health, which have not been answered yet [1]. Accordingly, the interest is focused more and more on the potential use of natural antioxidants for the stabilisation of polymers [e.g., 2-8]. The aim of our research was to find natural antioxidants, which can efficiently hinder the degradation of polyethylene during processing without any danger of possible health damage when dissolving from the polymer during application. The use of natural antioxidants eventually may even have some positive physiological effects. In this study we investigated the effect of curcumin on the processing stability of PE and compared to that of the most commonly used phenolic antioxidant, Irganox 1010 (see chemical structure in Table $1)$.

Curcumin, 1,7-bis(4-hydroxy-3-methoxyphenyl)-1,6-heptadiene-3,5-dione, is the principal curcuminoid of Curcuma longa rhizomes (turmeric). The curcuminoids are natural phenols that cause the yellow color of turmeric [9]. Curcumin is an oil-soluble pigment, practically insoluble in water at acidic and neutral $\mathrm{pH}$, and soluble in alkali [10]. Curcumin can exist in several tautomeric forms, including a 1,3-diketo form and two equivalent enol forms (Table 1). In solid state and in many solutions the planar enol form is more stable than 
the nonplanar diketo form [11], while the keto form predominates in acidic and neutral aqueous solutions and in the cell membrane [12]. Curcumin has superb antioxidant activity which was found to be stronger for the enol isomer than the for keto form [13]. This antioxidant has radical and hydrogen peroxyde scavenging, as well as metal chelating activities [e.g., 14-17]. Besides scavenging oxygen centred radicals curcumin also scavenges nitrogen centred free radicals $[18,19]$. The antioxidant and antifungal activities of curcumin is enhanced when used in combination with ascorbic acid [20].

Curcumin is not particularly stable to light, especially in solutions [10]. A cyclic as well as other decomposition products, such as vanillic acid, vanillin, and ferulic acid were detected in its solutions after photo-irradiation [10,21,22]. The photosenzitization of curcumin requires oxygen [23]. In solid state the intramolecular hydrogen bonding provides a channel for fast deactivation of excited states [24]. In solution the photochemical properties are strongly influenced by the type of solvent. In protic solvents, like ethanol, both parts of the curcumin molecule are involved in the excited singlet state. Curcumin photogenerates singlet oxygen, superoxide, as well as some carbon-centred radicals in this solvent [24].

Powdered turmeric rhizomes is used as food colorant, spice and food preservative. The medical activity of curcumin has been known since ancient times. As a consequence, the different effects and reactions of curcumin have been the subject of investigation in the fields of biology, medicine, pharmacology, as well as in the food industry for many years yielding a large number of publications. However, the actual reaction site and the mechanism of free radical scavenging have not been clarified yet. H-atom donation was found as a preferred reaction of curcumin at $\mathrm{pH} \leq 7$ and in nonprotic solvents [12]. Barclay et al. [25] observed that the antioxidant activities of o-methoxyphenols decreased in hydrogen bond accepting media. According to some authors the $\mathrm{OH}$ groups on the two phenyl rings participate in the reactions [e.g.,13,14,25], others claim that the $\beta$-diketone moiety is responsible for the 
antioxidant action [12], while other publications [26,27] indicate that the strong antioxidant activity of curcumin originates mainly from the phenolic $\mathrm{OH}$ groups, but a small fraction is due to the $>\mathrm{CH}_{2}$ site in the $\beta$-diketone moiety. Not only the site but also the reaction mechanism of antioxidant activity is controversial. Some authors [e.g., 12,26,28] proposed Hatom transfer (HAT), some others [29] suggested single electron transfer (SET) mechanism, while Litwinienko and Ingold [30,31] elaborated the Sequential Proton Loss Electron Transfer (SPLET) theory.

The antioxidant activity of curcumin is usually studied in solution at ambient temperature. The question is whether this natural antioxidant can keep its superb stabilising efficiency under the conditions of polyolefin processing $\left(190-260{ }^{\circ} \mathrm{C}\right.$, shear). We could not find any publication dealing with this aspect. In this work the stabilisation effect of curcumin was studied in polyethylene processed by multiple extrusions. The natural antioxidant was investigated as a singly stabiliser and in combination with a phosphorous secondary antioxidant, which plays an important role in the processing stabilisation of polyethylene $[32,33]$. The stabilising efficiency of curcumin was compared to that of a commonly used synthetic phenolic antioxidant.

\section{Experimental}

\subsection{Materials}

The experiments were carried out with the Tipelin FS 471 grade ethylene/1-hexene copolymer (melt flow rate of the powder: $0.32 \mathrm{~g} / 10 \mathrm{~min}$, nominal density: $0.947 \mathrm{~g} / \mathrm{cm}^{3}$ ) polymerized by a Phillips catalyst. The additive-free polymer powder was provided by Tisza Chemical Ltd. (TVK), Hungary. The polymer was stabilised with 1000 ppm curcumin (SigmaAldrich), and with a mixture of 1000 ppm curcumin and 2000 ppm Sandostab P-EPQ (P-EPQ; Clariant). Samples processed with the same amounts of Irganox 1010 (I1010; BASF 
Switzerland) and its combination with P-EPQ were used as references. The chemical structure of the investigated antioxidants, including the components of P-EPQ which is a mixture of three compounds, is shown in Table 1.

\subsection{Sample preparation}

The polymer and the additives were homogenized in a high speed mixer (Henschel $\mathrm{FM} / \mathrm{A} 10$ ) at a rate of $500 \mathrm{rpm}$ for $10 \mathrm{~min}$ then pelletized by six consecutive extrusions using a Rheomex S 3/4" type single screw extruder attached to a Haake Rheocord EU $10 \mathrm{~V}$ driving unit at $50 \mathrm{rpm}$ and barrel temperatures of $180,220,260$ and $260^{\circ} \mathrm{C}$. Samples were taken after each extrusion step. For further studies films of about $100 \mu \mathrm{m}$ and plates of $1 \mathrm{~mm}$ thickness were compression moulded at $190{ }^{\circ} \mathrm{C}$ using a Fontijne SRA 100 machine.

\subsection{Methods}

The chemical structure of curcumin and the functional groups (unsaturated and carbonyl) of polyethylene were investigated by FT-IR spectroscopy using a Tensor 27 (Bruker) type FT-IR spectrophotometer. Five parallel measurements were carried out on each sample. The concentration of vinyl and carbonil groups were determined from the absorbance spectra recorded on compression moulded polymer films by the internal standard method according to Eq. 1

$$
C=\frac{K}{\rho}\left(\frac{A_{i n v}}{A_{r e f}}\right)
$$

where $C$ is the concentration of a given functional group, $K$ is its absorption coefficient, $\rho$ is the density of the polymer $\left(\mathrm{g} / \mathrm{cm}^{3}\right)$, while $A_{i n v}$ and $A_{\text {ref }}$ are the intensities of the investigated and the reference absorption bands, respectively. We used the absorption band of the $-\mathrm{CH}$ vibration appearing at $2018 \mathrm{~cm}^{-1}$ as reference. A series of Phillips type ethylene/1-hexene 
copolymers with various butyl branching and unsaturations were investigated earlier to determine the absorption coefficient of vinyl group vibration (band at $\left.908 \mathrm{~cm}^{-1}\right)(K=0.5000)$. The concentration of the carbonyl groups was calculated from the integrated absorption intensity (TCO) of the vibration appearing in the range of $1780-1690 \mathrm{~cm}^{-1}(K=0.03826)$.

The photo stability of curcumin was studied by aging the material in powder form and in different solutions (ethanol, methanol, acetone, acetonitrile, toluol, chloroform) in natural light (behind a window), and in dark with periodical sampling for 5 months. $5 \mathrm{mg}$ of the sample was dissolved in $100 \mathrm{ml}$ solvent and analyzed by a HP 8452A type (Hewlett-Packard) UV-VIS spectrophotometer in the wavelength range of 190-820 $\mathrm{nm}$. The melting characteristics and thermal stability of curcumin as well as its 1:1 mixture with P-EPQ were studied using a Mettler TA 4000 Thermal Analyzer. Differential scanning calorimetric (DSC) measurements were carried out in a DSC-30 cell under nitrogen $(50 \mathrm{ml} / \mathrm{min})$ at a heating rate of $10{ }^{\circ} \mathrm{C} / \mathrm{min}$, from -50 to $300{ }^{\circ} \mathrm{C}$.

The rheological properties of the polymer were measured by two methods. MFR measurements were run according to the ASTM D 1238-79 standard at $190{ }^{\circ} \mathrm{C}$ with 2.16 load in a Göttfert MPS-D MFR tester. Creep curves were recorded at $190{ }^{\circ} \mathrm{C}$ with $500 \mathrm{~Pa}$ mean stress and $300 \mathrm{~s}$ creep/600 s recovery phase times using a Rheoplus/32 V3.40 type (Anton Paar) Universal Dynamic Spectrometer. Creep viscosity $\left(\eta_{0}\right)$ was derived from the compliance measured in the creep phase. The thermo-oxidative stability of the polymer was characterised by the oxidation induction time (OIT) measured at $200{ }^{\circ} \mathrm{C}$ by a Perkin Elmer DSC2 apparatus under oxygen. The colour of the samples was determined using a Hunterlab Colourquest 45/0 apparatus. Yellowness (YI) index was calculated as the characteristic parameter. 


\section{Results and discussions}

\subsection{Stability and interactions of curcumin}

We made an attempt to prove the H-bonding capability of curcumin by an FT-IR study carried out in methanol solution. Unfortunately we failed completely, because of the intense absorption of methanol made the determination any shift in absorption bands impossible. However, thermal analysis offered an indirect way to prove the existence of such molecular interactions. The melting traces of curcumin, P-EPQ, and the 1:1 mixture of curcumin and PEPQ (Fig. 1) were recorded under nitrogen after melting the materials in Ar atmosphere at $220{ }^{\circ} \mathrm{C}$ for $1 \mathrm{~min}$ followed by cooling to ambient temperature. The blend of the two additives, i.e. cucumin and P-EPQ was studied in a similar way. Equal amounts of the two powders were thoroughly mixed and melted under the conditions indicated above $\left(220{ }^{\circ} \mathrm{C}, \mathrm{Ar}\right)$. We assumed that after melting the mixture became homogeneous. Curcumin fuses at $179{ }^{\circ} \mathrm{C}$ then starts to decompose above $190{ }^{\circ} \mathrm{C}$ with an exothermal peak at $277{ }^{\circ} \mathrm{C}$. P-EPQ does not crystallise, it goes through glass transition with an overheating peak at $69.5^{\circ} \mathrm{C}$. The heat flow does not change up to $265{ }^{\circ} \mathrm{C}$ at which the substance starts to decompose giving an exothermal peak with a maximum at around $293{ }^{\circ} \mathrm{C}$. Interaction between curcumin and PEPQ in the mixture is indicated by the shift of the glass transition of P-EPQ to $66{ }^{\circ} \mathrm{C}$ and the disappearance of the fusion peak of curcumin. The mixture of the two additives is thermally less stable than the components themselves. These phenomena could be the result of $\mathrm{H}$ bonding or other intermolecular interactions. The reactions resulting in exothermal heat flow start at around $140{ }^{\circ} \mathrm{C}$ and show a maximum at $207^{\circ} \mathrm{C}$.

Curcumin was aged at ambient temperature in powder form and in methanol solution in dark and light for 147 days. The UV-VIS absorption spectra shown in Fig. 2 reveal that the chemical structure of the antioxidant does not change significantly when it is stored in powder form either in dark or in light for five months, which, according to literature references [24], 
can be explained with intramolecular hydrogen bonding that provides a channel for fast deactivation of excited states [24]. The oxygen penetration into the crystals is also slower in the solid resulting in slower decomposition, because of the absence of oxygen. Similarly, only a small change can be observed when curcumin is dissolved in methanol and stored in dark (Fig. 2). On the other hand, photochemical decomposition is revealed by the UV-VIS spectra when the antioxidant is stored in methanol solution in light (Fig. 3). The fragmentation of the molecule [22] is proved by the fast decrease in the intensity of the absorption bands appearing at 424 and $262 \mathrm{~nm}$ and the increase in those detected at 232 and $200 \mathrm{~nm}$ wavelengths.

In order to confirm the specific effect of H-bonding on the stability of curcumin, we carried out an ageing study in various solvents. Fig. 4 shows that in the two solvents which can form strong H-bonds with curcumin, i.e. in ethanol and methanol, degradation is much slower than in any of the other solvents thus proving the important role of specific interactions on curcumin stability. These results are in accordance with the work of Nardo et al. [34]. Electronically excited $\beta$-diketones can deactivate in the fastest way by excited-state intramolecular proton transfer (ESIPT). Intermolecular H-bond formation heavily perturbs intramolecular H-bonding. The higher the ESIPT rate is the tighter the intramolecular H-bond is between the enol and the keto moiety.

\subsection{Processing stabilisation}

The vinyl group concentration of the nascent polymer powder decreases the most significantly (from 0.983 to 0.805 vinyl $/ 1000 \mathrm{C}$ ) in the first extrusion then the change becomes smaller in further processes (Fig. 5). The total decrease is only 0.025 vinil/1000 C in the five consecutive extrusions. The composition of the stabiliser system does not influence significantly the vinyl group content of the polymer. This result means that curcumin does not change the reactions of the vinyl groups during processing compared to the effect of I1010. 
Curcumin hinders the oxidation of polyethylene during processing more efficiently than I1010 (Fig. 6). Carbonyl groups do not form in its presence or when its combination with PEPQ is used, while the oxidation of the polymer stabilised with the synthetic phenolic antioxidant is proved by the carbonyl concentration which is larger than the one caused by $1000 \mathrm{ppm}$ I1010 (0.1 mmol CO/mol PE). The degree of oxidation is smaller when $\mathrm{I} 1010$ is combined with the phosphonite antioxidant.

Similarly to vinyl group content, the melt flow rate of the polymer decreases the most significantly in the first extrusion, in an extent depending on the amount of P-EPQ (from 0.32 $\mathrm{g} / 10 \mathrm{~min}$ to 0.17 and $0.20 \mathrm{~g} / 10 \mathrm{~min}$ at 0 and $2000 \mathrm{ppm}$ P-EPQ, respectively), as shown in Fig. 7. The addition of the phosphonite enhances the melt stabilising efficiency of both antioxidants, while the type of the phenol derivative does not influence the change significantly. In further extrusion processes the change in MFR is much smaller and the type of the phenol plays an essential role in its direction. In the presence of I1010 the decrease in MFR continues, while some increase can be observed with curcumin. This latter result indicates that besides chain extension processes (characteristic for the degradation of Phillips type polyethylenes) chain breaking also takes place. Similar conclusions can be drawn from the changes in creep viscosity plotted as a function of the number of extrusions in Fig. $8 . \eta_{0}$ increases considerably when I1010 is applied as a phenolic antioxidant, while it increases only slightly when the polymer is stabilised with curcumin or does not change when the curcumin/P-EPQ combination is used.

The residual thermo-oxidative stability of the polymer characterized by the oxidation induction time is influenced by both types of antioxidants (Fig. 9). Without phosphonite the phenolic antioxidants provides only moderate thermo-oxidative stability to the polymer, although stability is independent of the number of extrusions. OIT increases considerably when phenol/phosphonite antioxidant combinations are applied. With increasing number of 
extrusions the phosphonite is consumed and the thermo-oxidative stability of the polymer decreases. Fig. 9 also reveals that the same amount of curcumin is somewhat more efficient oxidative stabiliser than I1010, either alone or in combination with P-EPQ.

The yellowness index of the samples is plotted as a function of the number of extrusions in Fig. 10. I1010 discolours the polymer in a given degree, as known, and yellowness index increases with increasing number of extrusions. The addition of P-EPQ to I1010 improves the colour stability of the polymer, but some gradual yellowing cannot be avoided during multiple extrusions even in this case. Due to its original yellow colour, curcumin discolours the polymer quite strongly. The addition of P-EPQ to curcumin does not change yellowness index. In contrast to the effect of I1010, the YI of the samples stabilised with curcumin slightly decreases with increasing number of extrusions indicating that the heptadienone linkage between the two methoxyphenol rings of curcumin also participates in the chemical reactions taking place during the processing of polyethylene.

\subsection{Discussion}

The effect of curcumin on the processing stability of polyethylene can primarily be explained with its ability to scavenge free radicals. The oxidation of the macroradicals formed as an effect of heat and shear cannot be hindered in the first extrusion of the polymer powder, as it contains absorbed oxygen at a relatively large concentration [35]. As a consequence, the reactions of the polymer are controlled primarily by the number of unsaturated groups and the efficiency of the hydroperoxide decomposing phosphorous secondary antioxidant $[32,33]$. In further processes, in which thermal reactions dominate, the reaction mechanism of the phenolic antioxidant plays an important role. In the case of I1010 the abstraction of the Hatom from the phenolic $\mathrm{OH}$ group proceeds slower or with similar rate as the addition of macroradicals to vinyl groups resulting in the formation of long chain branches, an increase of 
viscosity and decrease of MFR. Due to its complex structure curcumin may participate in several types of reactions. It can donate $\mathrm{H}$ atoms not only from the phenolic $\mathrm{OH}$ groups but also from the linear linkage between the two methoxyphenyl rings. $\beta$-diketone radicals are assumed to form by $\mathrm{H}$ atom donation from the $\mathrm{CH}_{2}$ group of the heptadienone linkage [26] and they may react with the vinyl groups of the polymer and/or with macroradicals. Further radicals can form also by the thermal decomposition of curcumin, which is not the subject of investigation in the literature, since degradation is studied practically always in solution, generally at ambient temperature $[22,36]$. Further possibility is the addition of macroradicals to the unsaturated groups of the linear linkage of curcumin. The reactions of the radicals derived from curcumin through reactions with the vinyl group of the polymer, and the addition of macroradicals to the double bonds of curcumin can hinder the formation of long chain branches. In this case the molecular mass of the polymer decreases, which results in an increase of MFR and decrease of discolouration. The exact processing and thermo-oxidative stabilisation mechanism of curcumin in polyethylene needs further studies. Model experiments are in progress, and our first results show that curcumin is able to scavenge alkyl radicals indeed, while Irganox 1010 can not. This additional capability may result in the larger efficiency of curcumin compared to that of I1010.

\section{Conclusions}

Curcumin, a natural antioxidant, is stable as a crystalline solid at ambient temperature in air. It keeps its stability in different kind of solutions when stored in dark, but decomposes in light. Its rate of decomposition depends on the solvent used. Curcumin is thermally stable up to $190{ }^{\circ} \mathrm{C}$, but the interaction with a phosphonite stabiliser results in some decrease in the starting temperature of thermal decomposition. Curcumin is a more efficient melt and thermooxidative stabiliser of polyethylene than the synthetic phenolic antioxidant used as reference 
(I1010), and the addition of a phosphonite secondary stabiliser improves its efficiency further. Although the number of vinyl groups participating in chemical reactions during processing is similar in the case of the two phenolic derivatives, changes in the rheological properties and colour of the polymer reveal that the mechanism of their stabilization reactions differs. The synthetic phenolic antioxidant used cannot hinder reactions leading to the formation of long chain branches. In the presence of curcumin the melt flow rate of the polymer increases and its colour decreases with increasing number of extrusions. These changes indicate that besides the phenolic $\mathrm{OH}$ groups also the linear linkage between the two methoxyphenyl rings of curcumin participates in the stabilisation reactions.

\section{Acknowledgement}

The National Research Fund of Hungary (OTKA K 77860 and K 101124) is greatly acknowledged for the financial support of the research.

\section{References}

1. Brocca D, Arvin E, Mosbaek H. Identification of organic compounds migrating from polyethylene pipelines into drinking water. Water Res 2002;36:3675-3680.

2. Al-Malaika S, Ashley H, Issenhuth S. The antioxidant role of $\alpha$-tocopherol in polymers. I. The nature of transformation products of $\alpha$-tocopherol formed during melt processing of LDPE. J Polym Sci Part A: Polym Chem 1994;32:3099-3113.

3. Al-Malaika S, et al. The antioxidant role of vitamin E in polymers V. Separation of stereoisomers and characterisation of other oxidation products of $\mathrm{dl}-\alpha$-tocopherol formed in polyolefins during melt processing. Polym Degrad Stab 2001;73:491-503.

4. Alexy P, Košíková B, Podstránska G. The effect of blending lignin with polyethylene and polypropylene on physical properties. Polymer 2000;41:4901-4908. 
5. de Abreu DAP, Losada PP, Maroto J, Cruz JM. Natural antioxidant active packaging film and its effect on lipid damage in frozen blue shark (Prionace glauca). Innov Food Sci Emerg Technol 2011;12:50-55.

6. de Abreu DAP, Maroto J, Rodríguez KV, Cruz JM. Antioxidants from barley husks impregnated in films of low-density polyethylene and their effect over lipid deterioration of frozen cod (Gadus morhua). J Sci Food Agr 2012;92:427-432.

7. Cerruti P, Malinconico M, Rychly J, Matisova-Rychla L, Carfagna C. Effect of natural antioxidants on the stability of polypropylene films. Polym Degrad Stab 2009;94:20952100.

8. Ambrogi V, Cerruti P, Carfagna C, Malinconico M, Marturano V, Perrotti M, Persico P. Natural antioxidants for polypropylene stabilization. Polym Degrad Stab 2011;96:21522158.

9. Phytopharmaceuticals in Cancer Chemoprevention, CRC Press LLC 2005; Ed.: Bagchi D, Preuss HG, Chap. 23: Aggarwal BB, Kumar A, Aggarwal MS, Shishodia S. Curcumin Derived from Turmeric (Curcuma longa): a Spice for All Seasons p.: 350-351.

10. Curcumin. CTA. (First draft Stankovic I) 61st JECFA. FAO 2004. http://www.fao.org/fileadmin/templates/agns/pdf/jecfa/cta/61/Curcumin.pdf

11. Kolev TM, Velcheva EA, Stamboliyska BA, Spiteller M. DFT and experimental studies of the structure and vibrational spectra of curcumin. Int J Quantum Chem 2005;102:1069-1079.

12. Jovanovic SV, Steenken S, Boone CW, Simic MG. H-atom transfer is a preferred antioxidant mechanism of curcumin. J Am Chem Soc 1999;121:9677-9681.

13. Barzegar A. The role of electron-transfer and $\mathrm{H}$-atom donation on the superb antioxidant activity and free radical reaction of curcumin. Food Chem 2012;135:1369-1376.

14. Ak T, Gülçin I. Antioxidant and radical scavenging properties of curcumin. Chemico- 
Biol Interact 2008;174:27-37.

15. Borsari M, Ferrari E, Grandi R, Saladini M. Curcuminoids as potential new ironchelating agents: spectroscopic, polarographic and potentiometric study on their Fe(III) complexing ability. Inorg Chim Acta 2002;328:61-68.

16. Agnihotri N, Mishra PC. Scavenging mechanism of curcumin toward the hydroxyl radical: A theoretical study of reactions producing ferulic acid and vanilin. J Phys Chem 2011;115:14221-1432.

17. Anto RJ, Kuttan G, Dinesh Babu KV, Rajasekharan KN, Kuttan R. Anti-tumour and free radical scavenging activity of synthetic curcuminoids. Int J Pharm 1996;131:1-7.

18. Unnikrishnan MK, Rao MNA. Curcumin inhibits nitrogen dioxide induced oxidation of hemoglobin. Mol Cell Biochem 1995;146:35-37.

19. Sreejayan N, Rao MNA. Free radical scavenging activity of curcuminoids. ArzneimForsch/Drug Res 1996;46:169-171.

20. Khalil OAK, de Faria Oliveira OMM, Vellosa JCR, de Quadros AU, Dalposso LM, Karam TK, Mainardes RM, Khalil NM. Curcumin antifungal and antioxidant activities are increased in the presence of ascorbic acid. Food Chem 2012;133:1001-1005.

21. Tonnesen HH, Greenhill JV. Studies on curcumin and curcuminoids. XXII: Curcumin as a reducing agent and as a radical scavenger. Int J Pharmaceut 1992;87:79-87.

22. Sundaryono A, Nourmamode A, Gardrat C, Grelier S, Bravic G, Chasseau D, Castellan A. Studies on the photochemistry of 1,7-diphenyl-1,6-heptadiene-3,5-dione, a nonphenolic curcuminoid model. Photochem Photobiol Sci 2003;2:914-920.

23. Dahl TA, McGowan WM, Shand MA, Srinivasan VS. Photokilling of bacteria by natural dye curcumin. Arch Mikrobiol 1989;151:183-185.

24. Chignell CF, Bilski P, Reszka KJ, Motten AG, Sik RH, Dahl TA. Spectral and photochemical properties of curcumin. Photochem Photobiol 1994;59:295-302. 
25. Barclay LRC, Vinqvist MR, Mukai K, Goto H, Hashimoto Y, Tokunaga A, Uno H. On the antioxidant mechanism of curcumin: classical methods are needed to determine antioxidant mechanism and activity. Org Lett 2000;2(18):2841-2843.

26. Priyadarsini KI, Maity DK, Naik GH, Kumar MS, Unnikrishnan MK, Satav JG, Mohan $\mathrm{H}$. Role of phenolic $\mathrm{O}-\mathrm{H}$ and methylene hydrogen on the free radical reactions and antioxidant activity of curcumin. Free Radical Bio Med 2003;35:475-484.

27. Kim MK, Jeong W, Kang J, Chong Y. Significant enhancement in radical-scavenging activity of curcuminoids conferred by acetoxy substituent at the central methylene carbon. Bioorg Med Chem 2011;19:3793-3800.

28. Gorman AA, Hamblett I, Srinavasan VS, Wood PD. Curcumin-derived transients: a pulsed laser and pulse radiolysis study. Photochem Photobiol 1994;59:389-398.

29. Galano A, Álvarez-Diduk R, Ramírez-Silva MT, Alarcón-Ángeles G, Rojas-Hernández. Role of the reacting free radicals on the antioxidant mechanism of curcumin. Chem Phys $2009 ; 363: 13-23$.

30. Litwinienko G, Ingold KU. Abnormal solvent effects on hydrogen atom abstraction. 2. Resolution of the curcumin antioxidant controversy. The role of sequential proton loss electron transfer. J Org Chem 2004;69:5888-5896.

31. Litwinienko G, Ingold KU. Solvent effects on the rates and mechanisms of reaction of phenols with free radicals. Acc Chem Res 2007;40:222-230.

32. Kriston I, Orbán-Mester Á, Nagy G, Staniek P, Földes E, Pukánszky B. Melt stabilisation of Phillips type polyethylene, Part I: The role of phenolic and phosphorous antioxidants, Polym Degrad Stab 2009;94:719-29.

33. Kriston I, Orbán-Mester Á, Nagy G, Staniek P, Földes E, Pukánszky B. Melt stabilisation of Phillips type polyethylene, Part II: Correlation between additive consumption and polymer properties, Polym Degrad Stab 2009;94:1448-56. 
34. Nardo L, Paderno R, Andreoni A, Másson M, Haukvik T, Tonnesen HH. Role of H-bond formation in the photoreactivity of curcumin. Spectroscopy 2008;22:187-198.

35. Epacher E, Tolvéth J, Kröhnke C, Pukánszky B. Processing stability of high density polyethylene: effect of adsorbed and dissolved oxygen. Polymer 2000;41:8401-8408.

36. Wang Y-J, Pan M-H, Cheng A-L, Lin L-I, Ho Y-S, Hsieh C-Y, Lin J-K. J Pharmaceut Biomed Anal 1997;15:1867-1876. 
Table 1

Chemical composition of the antioxidants studied

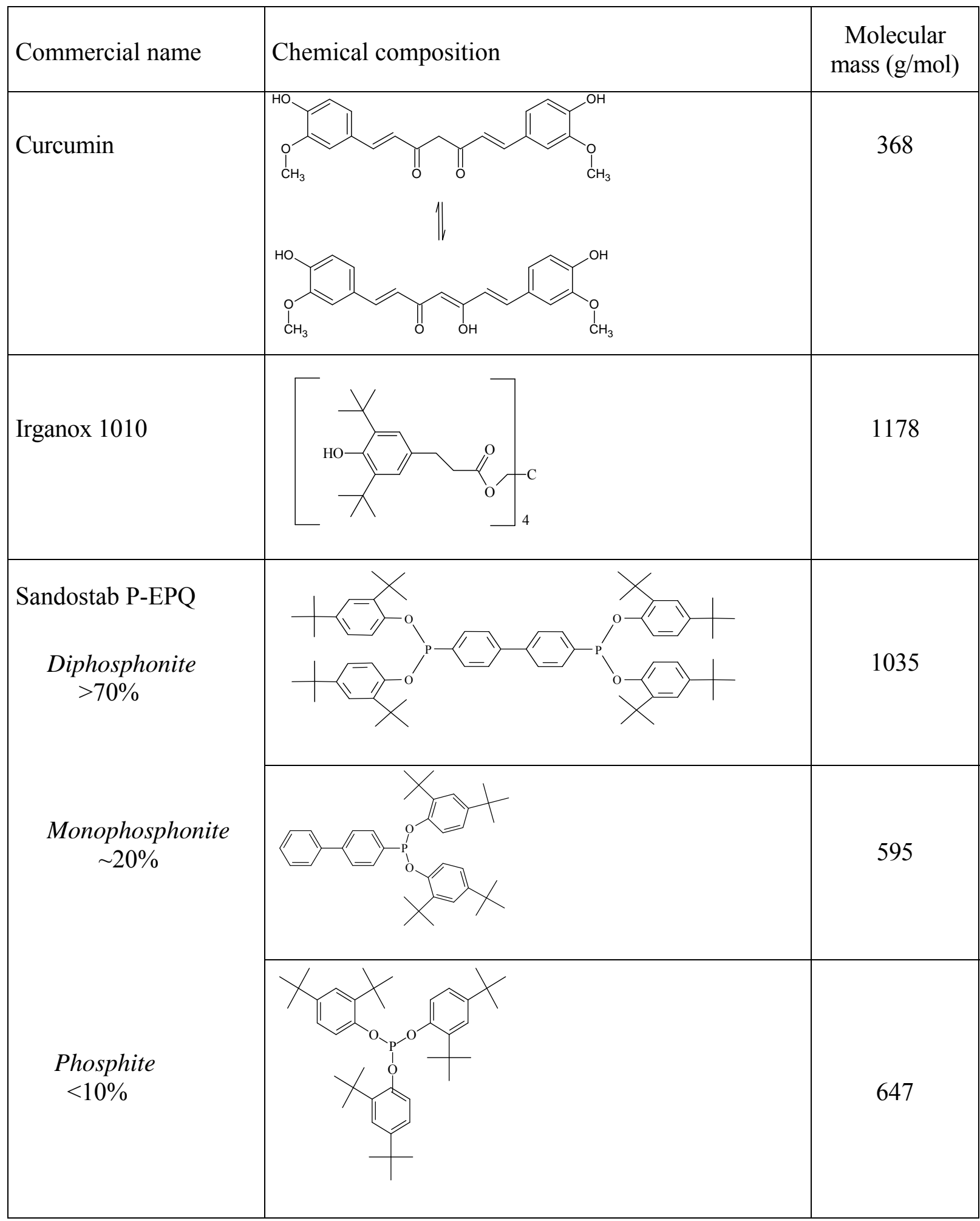




\section{Figure captions}

Fig. 1 Thermograms (melting) of curcumin, P-EPQ, and a 1:1 mixture of curcumin and PEPQ measured under nitrogen after melting in Ar atmosphere at $220^{\circ} \mathrm{C}$ for $1 \mathrm{~min}$ and then cooling down to ambient temperature. Heating rate: $10^{\circ} \mathrm{C} / \mathrm{min}$.

Fig. 2 UV-VIS spectra of curcumin recorded before aging (-), and after aging at ambient temperature for 147 days in powder form in dark (-- $)$ and light (---.), as well as in methanol solution in dark (*.).

Fig. 3 UV-VIS spectra of curcumin measured before aging (-), and after aging in methanol solution in light at ambient temperature for various times: - - - 17, -.$28,-\cdot-\cdot 56$, and $\cdots \cdot 147$ days.

Fig. 4 The stabilization effect of H-bonds on the light stability of curcumin in solution. Solvents: $(\bigcirc)$ ethanol, $(\square)$ methanol, $(\triangle)$ acetone, $(\diamond)$ acetonitrile, $(\triangleright)$ toluol, $(\nabla)$ chloroform

Fig . 5 Effect of the number of extrusions on the vinyl group content of polyethylene stabilised with 1000 ppm curcumin (०), 1000 ppm curcumin + 2000 ppm P-EPQ (•), 1000 ppm I1010 (口), and 1000 ppm I1010 + 2000 ppm P-EPQ (ロ).

Fig. 6 Effect of the number of extrusions on the carbonyl group content of polyethylene stabilised with 1000 ppm curcumin (०), 1000 ppm curcumin + 2000 ppm P-EPQ (•), 1000 ppm I1010 (口), and 1000 ppm I1010 + 2000 ppm P-EPQ (ロ).

Fig. 7 Effect of the number of extrusions on the melt flow rate of polyethylene stabilised with 1000 ppm curcumin (०), 1000 ppm curcumin + 2000 ppm P-EPQ (•), 1000 ppm I1010 (ם), and 1000 ppm I1010 + 2000 ppm P-EPQ (ロ) Neat powder ( $\mathbf{\Delta}$ ).

Fig. 8 Effect of the number of extrusions on the creep viscosity of polyethylene stabilised with 1000 ppm curcumin (०), 1000 ppm curcumin + 2000 ppm P-EPQ (•), 1000 ppm I1010 (ם), and 1000 ppm I1010 + 2000 ppm P-EPQ (匹). 
Fig. 9 Effect of the number of extrusions on the residual thermo-oxidative stability of polyethylene stabilised with $1000 \mathrm{ppm}$ curcumin (०), $1000 \mathrm{ppm}$ curcumin +2000 ppm P-EPQ (•), 1000 ppm I1010 (), and 1000 ppm I1010 + 2000 ppm P-EPQ (ロ).

Fig. 10 Effect of the number of extrusions on the yellowness index of polyethylene stabilised with 1000 ppm curcumin (o), 1000 ppm curcumin +2000 ppm P-EPQ (•), 1000 ppm I1010 (口), and 1000 ppm I1010 + 2000 ppm P-EPQ (ロ). 
Fig. 1

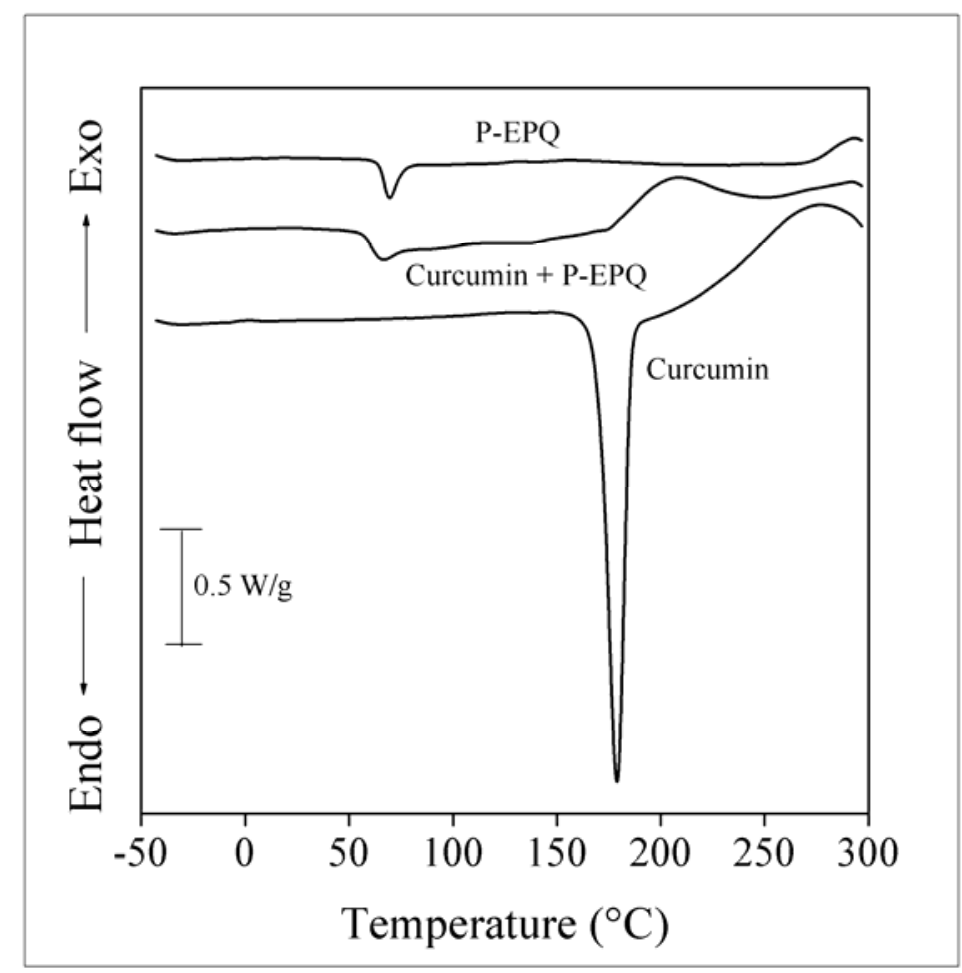


Fig. 2

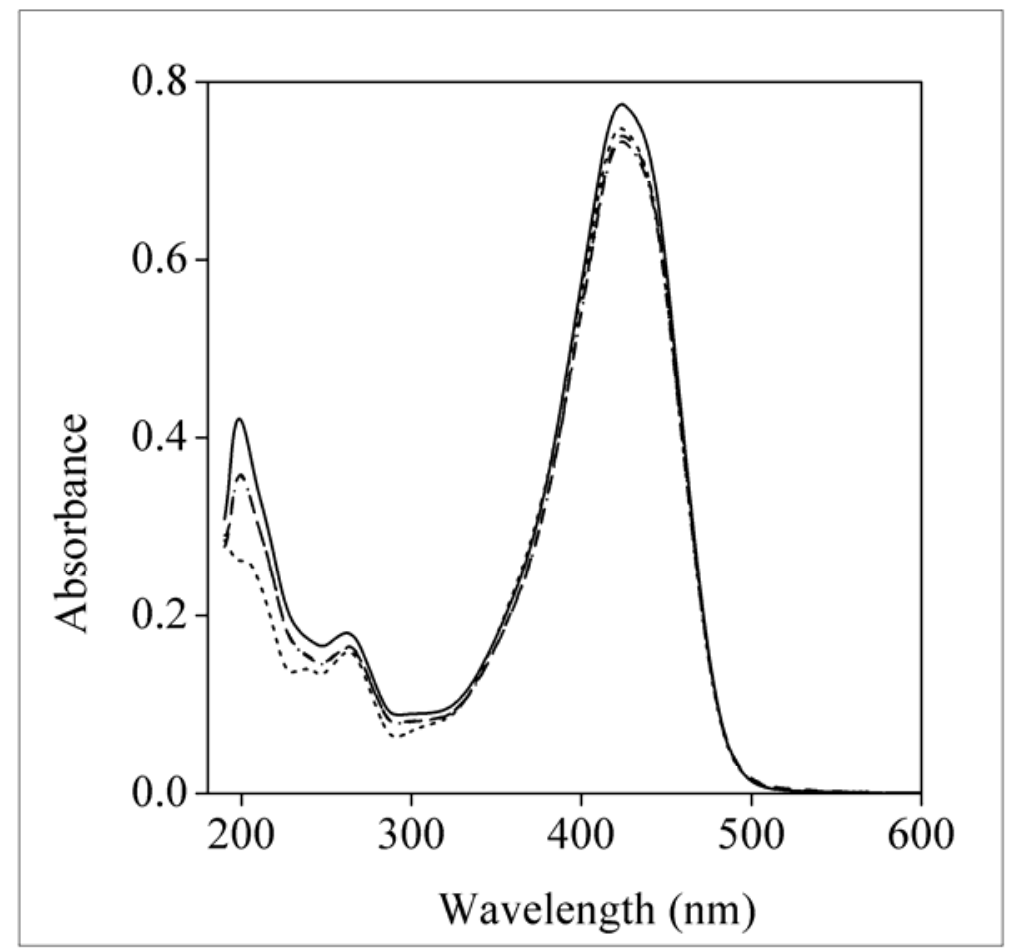


Fig. 3

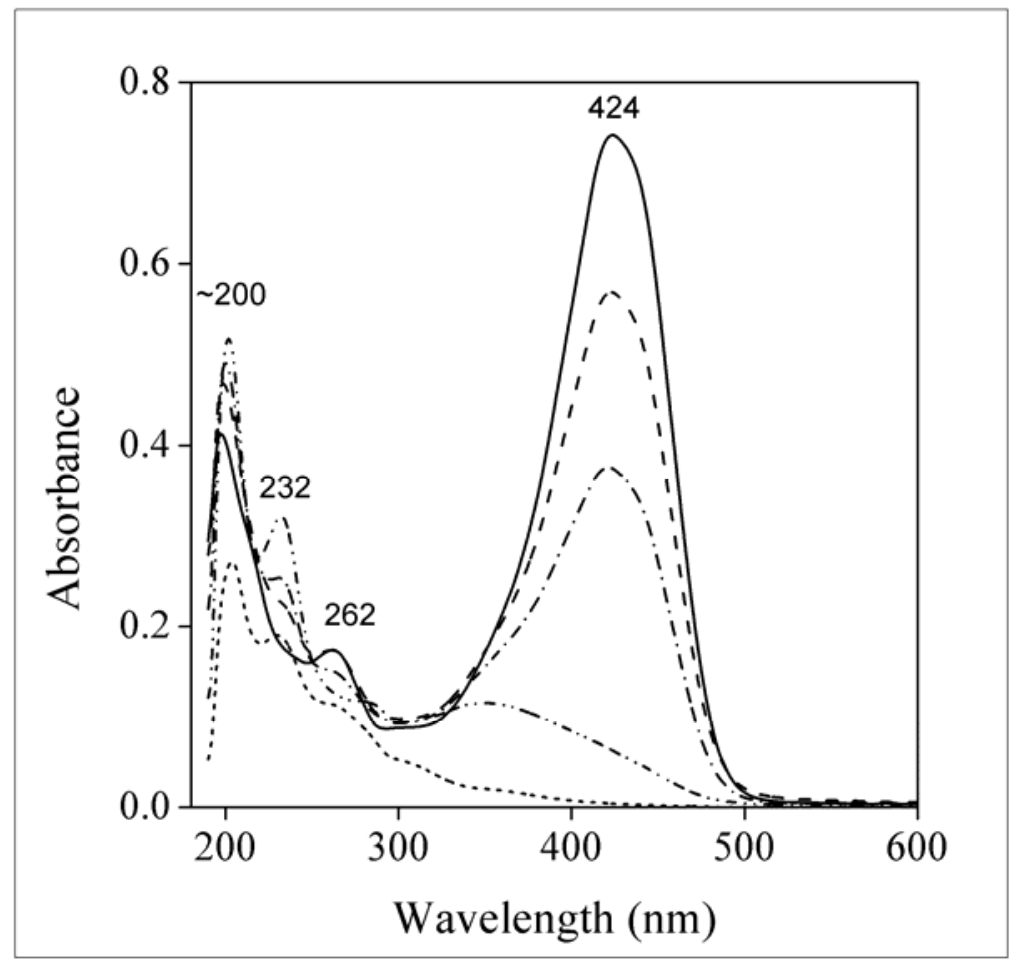


Fig. 4

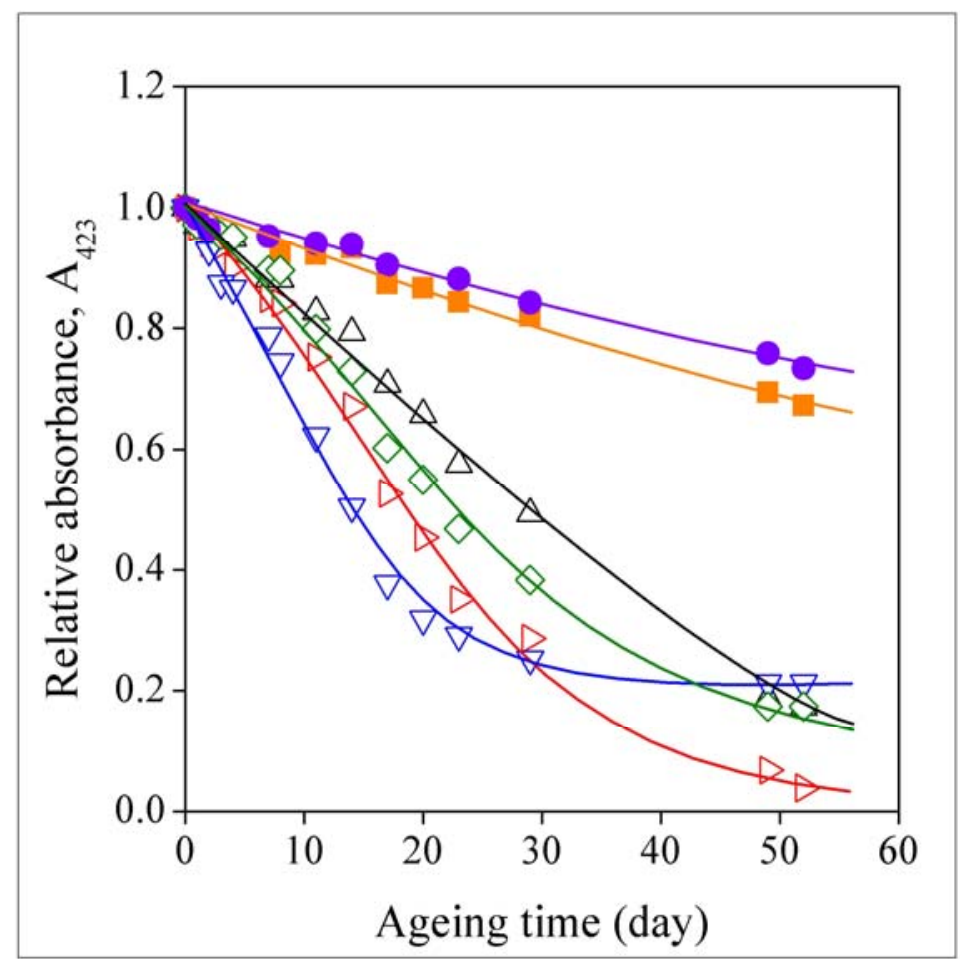


Fig. 5

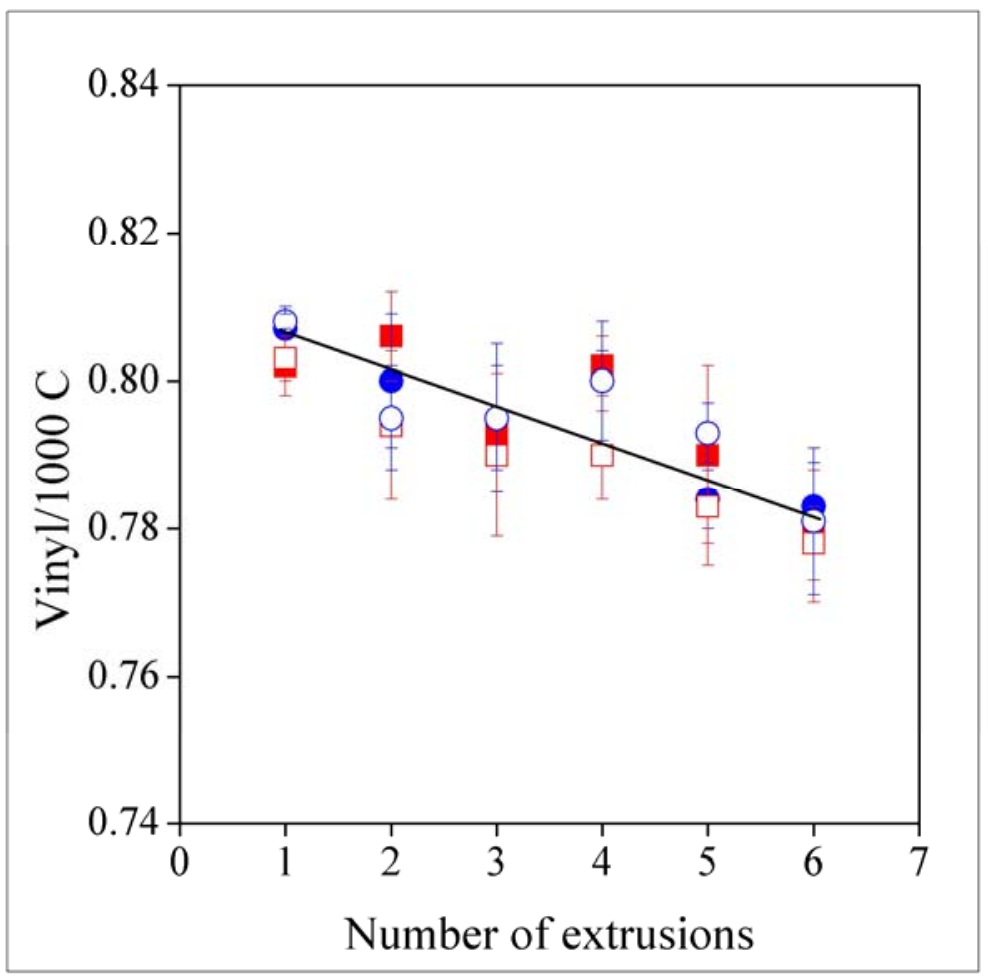


Fig. 6

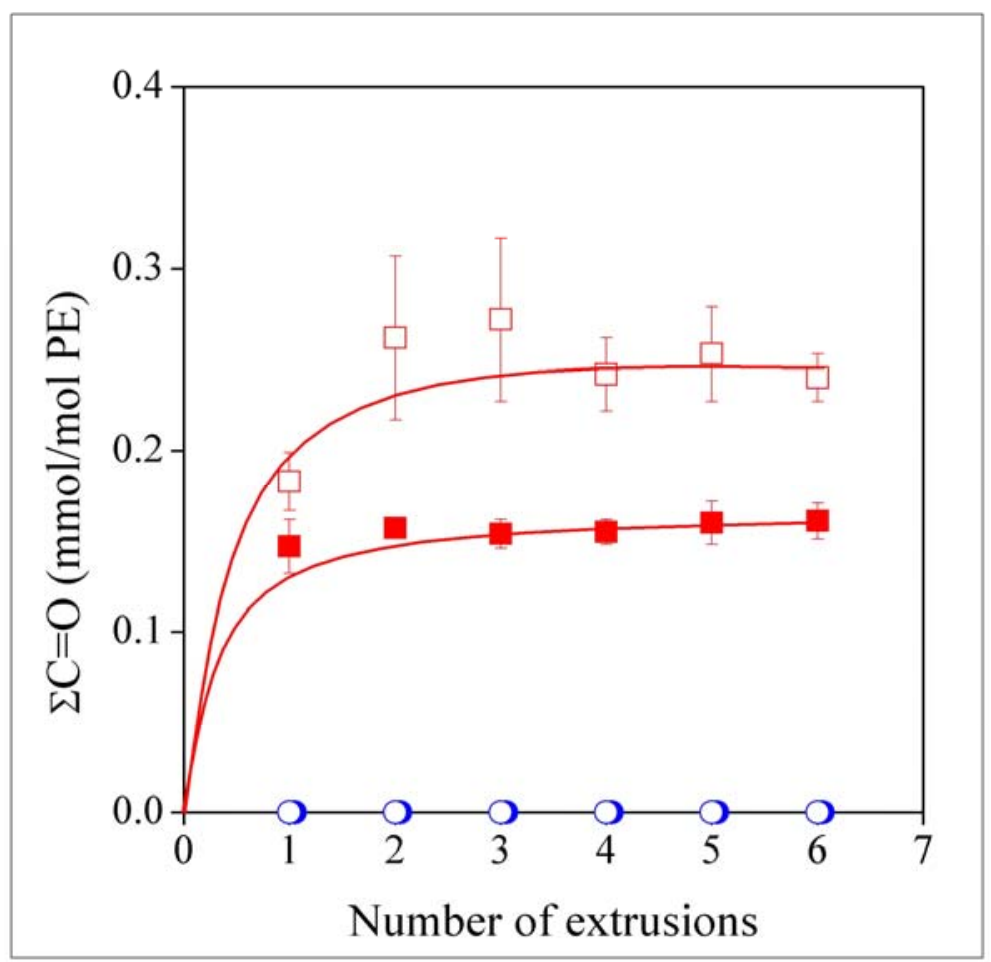


Fig. 7

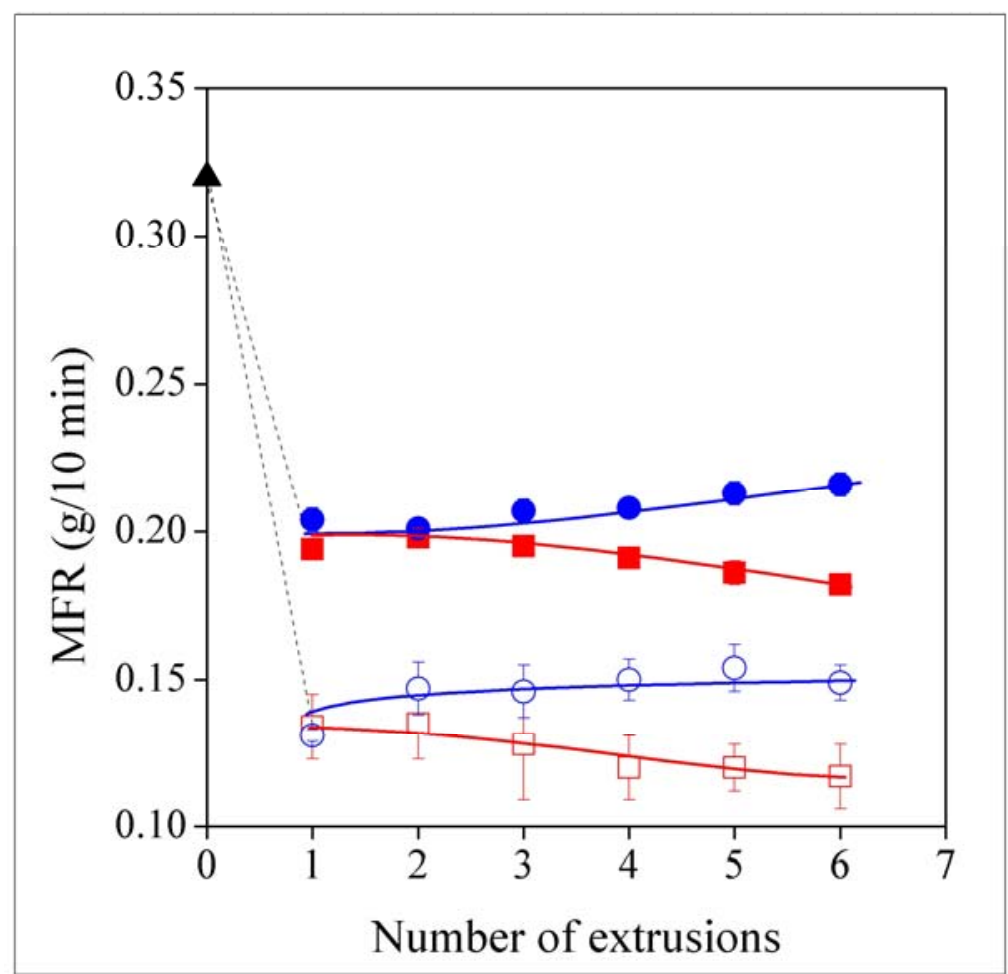


Fig. 8

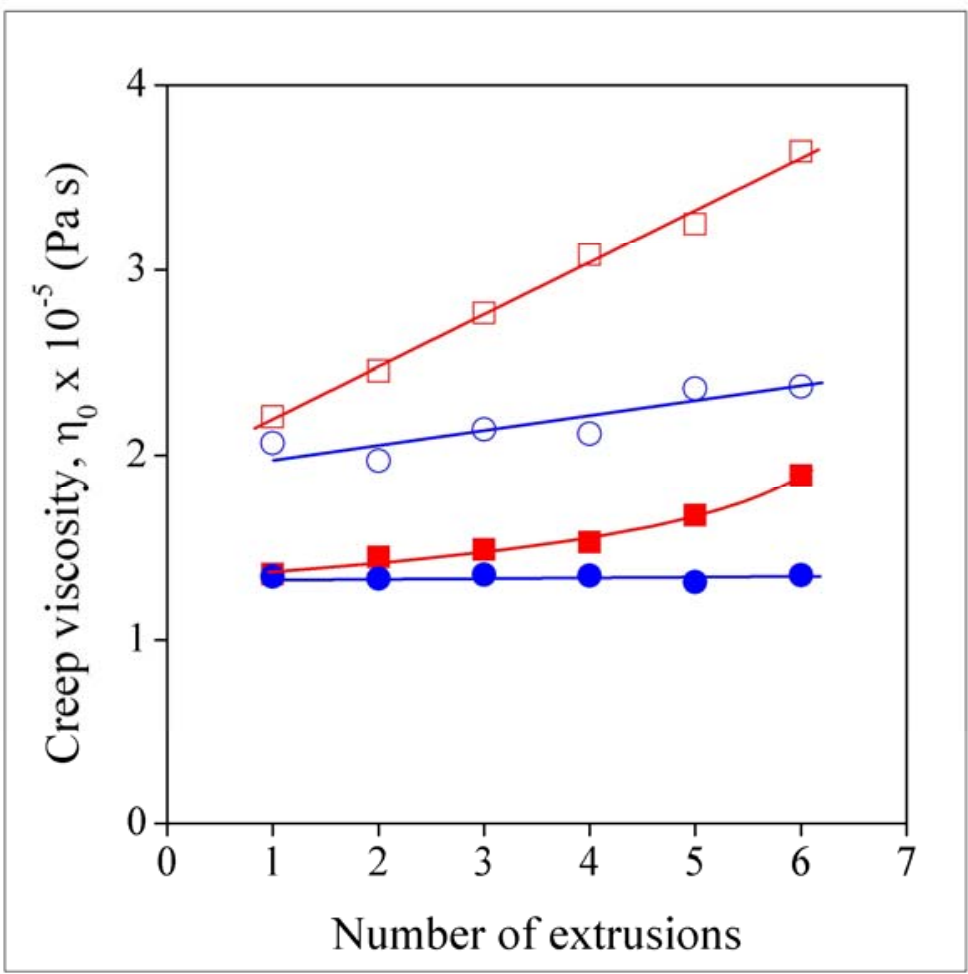


Fig. 9

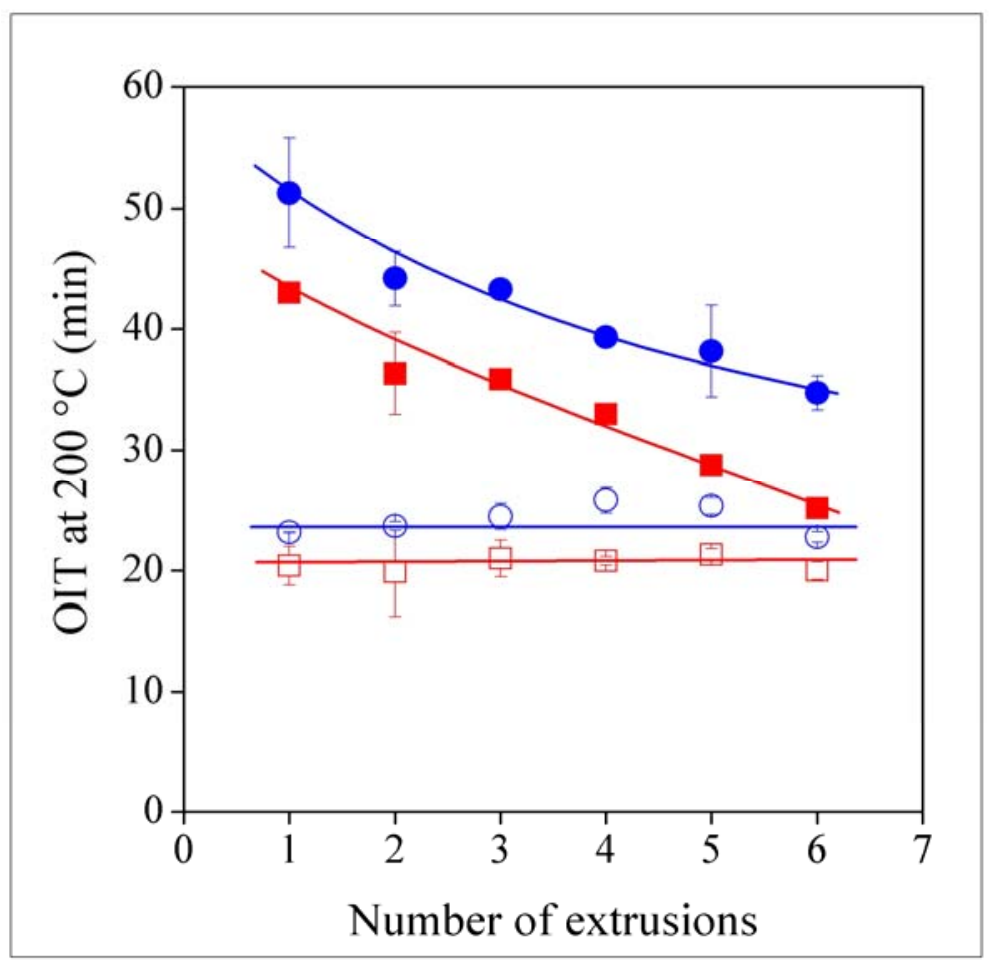


Fig. 10

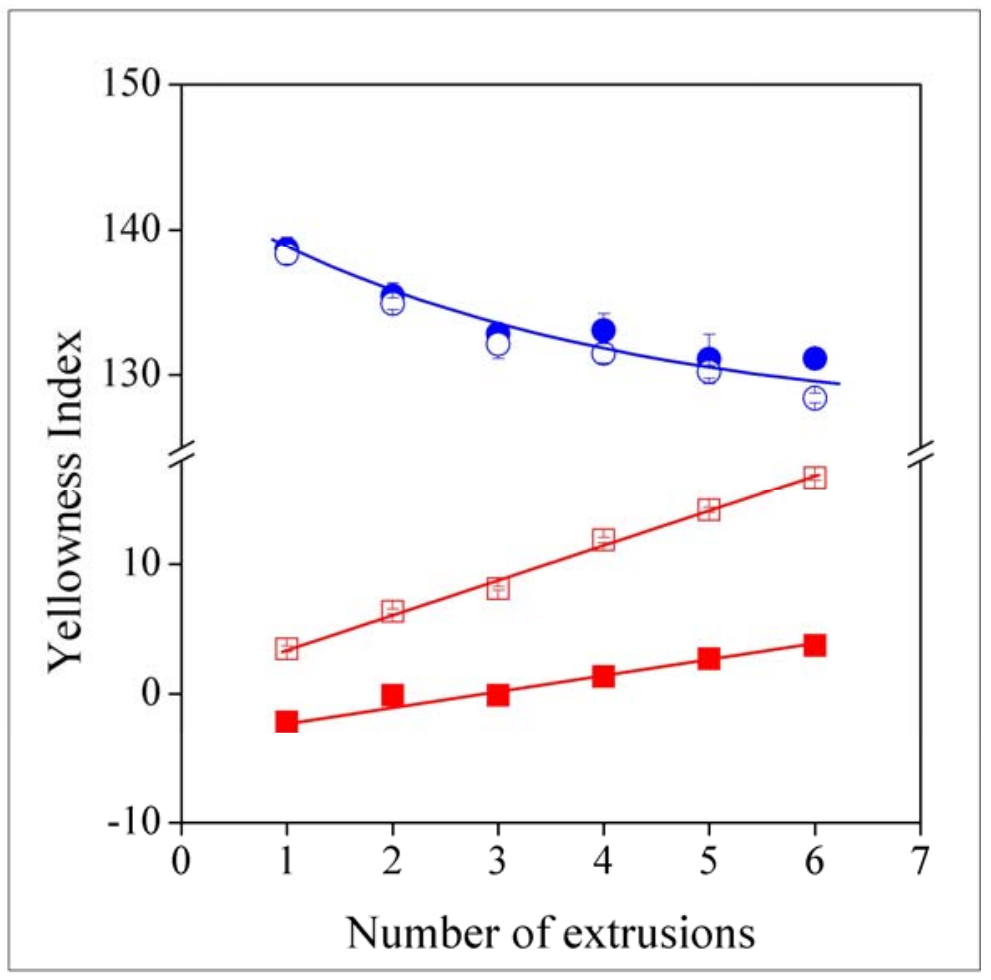

